\title{
Terrigenous deposits in coastal marine habitats: influences on sediment geochemistry and behaviour of post-settlement bivalves
}

\author{
Vonda Cummings ${ }^{1, *}$, Kay Vopel $^{2,3}$, Simon Thrush ${ }^{2}$ \\ ${ }^{1}$ National Institute of Water and Atmospheric Research, Private Bag 14-901, Wellington, New Zealand \\ ${ }^{2}$ National Institute of Water and Atmospheric Research, PO Box 11-115, Hamilton, New Zealand \\ ${ }^{3}$ Present address: Auckland University of Technology, Private Bag 92006, Auckland, New Zealand
}

\begin{abstract}
Dispersal of post-settlement juvenile macrofauna is widespread in the marine environment, yet the cues used by these organisms to assess substrate suitability are poorly known. We investigated how deposition of fine terrestrial sediments (TS, 0.5 to $1.7 \mathrm{~mm}$ thick) affects both the solute concentrations at the sediment-water boundary and the burrowing behaviour of juvenile tellinid bivalves Macomona liliana. To elucidate previously observed gradual reduction in the strength of macrofaunal responses with increasing age of deposits, the effect of TS weathered in the field for 0, 7 and $14 \mathrm{~d}$, and the influence of surface and buried TS layers, were also investigated. Burrowing was significantly reduced in 0 and $7 \mathrm{~d}$ old surface TS compared with controls, but there was no effect of buried deposits on M. liliana burrowing, irrespective of sediment age. Microelectrode measurements showed that thin surface TS layers reduced the supply of $\mathrm{O}_{2}$ to the underlying sediment, raising the position of the vertical $\left[\mathrm{O}_{2}\right]$ and $\mathrm{pH}$ gradients so that most of the gradient was located in the TS layer itself, rather than deeper in the sediment below it. Consequently, the likelihood of juveniles that are active in the near-surface layers being exposed to upward diffusing end products of microbial decomposition was increased. These results suggest a mechanism for the observed negative response of post-settlement $M$. liliana (and other macrofauna) to TS deposits associated with sedimentation events, and an avenue for further research into potential geochemical cues (especially $\mathrm{pH}$ and associated geochemical species).
\end{abstract}

KEY WORDS: Soft sediment $\cdot$ Terrestrial deposits $\cdot$ Settlement cues $\cdot$ Macomona liliana $\cdot \mathrm{pH} \cdot \mathrm{O}_{2} \cdot$ Diffusivity $\cdot$ Diffusive oxygen uptake $\cdot$ Microprofiles

\section{INTRODUCTION}

Dispersal of post-settlement juvenile stages of macrobenthic invertebrates is frequent and widespread in the marine environment (Beukema \& Vlas 1989, Gunther 1992, Commito et al. 1995), and is important in the regulation and organisation of benthic populations and communities (Dayton et al. 1994, Norkko et al. 2001). In environments such as estuaries, which have a high proportion of direct developing species (Stocks 2002), dispersal of post-settlement life stages is especially important in the maintenance of population con- nectivity and persistence. In soft-sediment systems, such dispersal can occur both passively, in association with sediment bedload transport (Emerson \& Grant 1991, Commito et al. 1995), and actively (e.g. Sigurdsson et al. 1976, Butman 1987). Upon arrival at a potential settlement site, individuals will encounter a sediment surface and make a decision concerning its acceptability; juveniles that accept the substrate will bury into the sediment, while those that reject the substrate will not. The cues used by post-settlement organisms to make settlement decisions are poorly known. For soft-sediment macrofauna, experimental 
work has demonstrated responses to chemicals associated with other fauna (Woodin 1985, Woodin et al. 1993), sediment food quality (Nilsson et al. 2000, Stocks \& Grassle 2001), and the presence of other fauna (Cummings et al. 1996, Olivier et al. 1996, Dahms et al. 2004).

Marinelli \& Woodin (2004) suggest that the acceptability of sediments to new colonists is influenced by transport and reaction processes that determine gradients in the concentrations of porewater solutes. The reaction processes within the sediment cause the production or consumption of solutes via either biologically mediated (e.g. photosynthesis of microphytes and bacterial mineralization of organic matter) or abiotic means (e.g. mineral dissolution, Jørgensen \& Boudreau 2001). Transport processes such as diffusion and advection displace solutes within the sediment and through the sediment-water interface. Disturbance of the sediment-water interface can result in short- and long-term modifications of such gradients, thus potentially affecting colonisation of the sediment. Larvae and juveniles of some species can differentiate between disturbed and undisturbed surface (top few $\mathrm{mm}$ ) sediments in response to short-term (min to h) changes in gradients of porewater $\mathrm{O}_{2}$ and ammonium (Woodin et al. 1995, Woodin 1998, Marinelli \& Woodin 2002, 2004). Periodic/recurring short-term changes in porewater solute gradients may result from, for example sediment disruptions by the activity of animals, or by wind-waves (Vopel et al. 2007). In contrast, disturbances that involve changes in the solid phase of the sediment can modify solute gradients at the sediment-water interface more persistently (Williamson et al. 1999, Glud et al. 2007).

An example of a persistent and large-scale disturbance is the deposition of terrigenous sediments in coastal environments (e.g. Milliman \& Meade 1983, Thrush et al. 2004). Terrigenous sediments are often supplied to coastal habitats during discrete rainfall events, as suspended matter via waterways, and/or directly as a result of landslides. Thick $(>2 \mathrm{~cm})$ terrestrial sediment (TS) deposits require significant exposure to wind and waves, or remobilization by crabs during their burrowing activities to become dispersed (Norkko et al. 2002). Thinner layers (3 to $10 \mathrm{~mm}$ ) remain visually obvious on sandflats even $10 \mathrm{~d}$ after their deposition (Lohrer et al. 2004). Layer thickness decreases over time due to gradual erosion, and/or mixing with ambient sand washed in from the surrounding sandflat. Moreover, the properties of the deposits change over time, with coarse sand and chlorophyll a levels increasing and organic content decreasing (Norkko et al. 2002, Cummings et al. 2003, Lohrer et al. 2004). Thus, it is obvious how TS that are deposited atop marine sediments may alter sedimen- tary transport and reaction processes and, consequently, any associated geochemical signals.

Field experiments have shown that deposition of thick $(>2 \mathrm{~cm}$ ) TS layers often results in mass mortality of resident infauna, and that recovery is very slow (i.e. years; Norkko et al. 2002, Cummings et al. 2003). Thinner deposits (1 to $20 \mathrm{~mm}$ ) also negatively affect macrofaunal communities, causing declines in densities of common species, and in total numbers of taxa and individuals (Thrush et al. 2003, Lohrer et al. 2004). Furthermore, post-settlement bivalves exposed to TS deposits exhibit reduced burrowing rates and dispersal abilities, suggesting that settlement on such deposits can have a lasting effect, even if an individual is able to find a more suitable habitat at a later date (Cummings \& Thrush 2004). These observations may partially be explained by modification of porewater solute transport and reaction processes by the TS deposits.

This paper describes a laboratory experiment designed to mimic the effects of thin $(<1.7 \mathrm{~mm})$ deposits of TS on sandflats in order to understand the resulting biogeochemical changes, and to better interpret the observed responses of post-settlement bivalve colonists. Changes in the physicochemical properties of the surface sediments were investigated at a micro-scale, relevant to an individual potential colonist's site choice. We used surface and buried deposits of fresh and weathered TS to account for the 2 in situ observations mentioned above: (1) over time, TS deposits may remain intact on the surface of the sediment or become gradually buried as they get covered by surrounding sediment transported as bedload (Norkko et al. 2002, Lohrer et al. 2004); and (2) the physicochemical properties of TS change with increasing length of exposure to the environment ('age'; see Cummings et al. 2003, Lohrer et al. 2004).

We chose post-settlement juveniles of the tellinid bivalve Macomona liliana (Iredale, 1915) as the study organism. M. liliana are common in New Zealand benthic communities, and are highly mobile postsettlement dispersers (e.g. Norkko et al. 2001). $\mathrm{O}_{2}$ was measured because of its role in multiple metabolic processes and its strong influence on the gradients of other redox-active porewater solutes (Jørgensen \& Boudreau 2001). pH was studied as it is considered a master variable that is linked to all major biogeochemical reaction processes in sediments (Jourabchi et al. 2005). Furthermore, $\mathrm{pH}$ influences the toxicity of several chemical species (e.g. $\mathrm{H}_{2} \mathrm{~S}, \mathrm{NH}_{3}$ i Ben-Yaakov 1973, Boudreau \& Canfield 1988, Bagarinao 1992), shell formation (e.g. Green et al. 2004, Gazeau et al. 2007) and likely also the physiological condition of benthic organisms (Kleypas et al. 2006), particularly the early life history stages. Concentration gradients of solutes at the sediment-water interface result from 
their production and consumption, and the impedance by the sediment of their diffusive transport. To characterise the latter variable, we measured the apparent diffusivity of the TS deposits.

\section{MATERIALS AND METHODS}

Experimental design. To investigate the effects of TS deposits on the burrowing behaviour of Macomona liliana juveniles, and on porewater gradients in $\mathrm{O}_{2}$ concentration (hereafter $\left[\mathrm{O}_{2}\right]$ ) and $\mathrm{pH}$, a series of experiments was conducted in low-flow aquaria in a constant temperature laboratory. We measured changes in the microprofiles of $\mathrm{O}_{2}$ and $\mathrm{pH}$ in response to TS deposits, and the burial responses of juvenile bivalves into the same sediments. We chose 3 sediment treatments: surface TS deposits (TS-surface), buried TS deposits (TSburied), and natural surface sediments obtained from the site where the juvenile Macomona liliana were collected (control sediment, C). The first 2 treatments were designed to reflect the fact that TS deposits may remain intact on the surface of the sandflat (TSsurface) or may become buried by ambient sediment moving with bedload (TS-buried). The TS-surface treatment consisted of $3 \mathrm{~cm}$ of control sediment, which was covered by a thin $(<1.7 \mathrm{~mm})$ layer of TS. The TSburied treatment consisted of $3 \mathrm{~cm}$ of control sediment, which was covered by a thin layer of TS and a $\sim 1 \mathrm{~mm}$ thick layer of control sediment. The control sediment treatment consisted of $3 \mathrm{~cm}$ of sediment only. To investigate the responses of Macomona liliana juveniles to deposits of TS that were weathered for different periods, 3 separate experiments were conducted using TS that mimicked new deposits (0 d old, run A), or had been aged in the field by deposition onto an intertidal sandflat for $7 \mathrm{~d}$ (run B) or $14 \mathrm{~d}$ (run C). The different TS ages are hereafter referred to as $0 \mathrm{~d}$ TS, $7 \mathrm{~d}$ TS and $14 \mathrm{~d}$ TS. Four replicates were used per treatment per run.

Sediments and bivalves. TS was obtained from the catchment above Mahurangi Harbour, on the east coast of the northern North Island, New Zealand. This is typical of the TS which is washed into New Zea- land's North Island estuaries and harbours during storms/heavy rain events. The 'source plot' of TS was established at mid-tide level on the Wairoa Island sandflat at Manukau Harbour, Auckland, in the following way: TS was mixed with seawater (50:50 seawater:sediment) and deposited into a $2 \mathrm{~m}$ diameter area on the sandflat to a depth of $5 \mathrm{~cm}$. The 7 and $14 \mathrm{~d}$ TS were collected from this source plot at the beginning of their respective runs, 7 and 14 d later, respectively. The $0 \mathrm{~d}$ TS was an identical mix that had not been deposited on the sandflat. The TS was predominantly comprised of fine sand in all runs (78 to $80 \%$ of volume), with a significant portion of silt (8 to 15\%; Table 1). The $7 \mathrm{~d}$ TS (run B) contained slightly more medium sand, and less silt than the 0 or the $14 \mathrm{~d}$ TS (i.e. 3.5 to $4.5 \%$ differences; Table 1). Control sediment and juveniles of Macomona liliana were collected from the Wairoa Island sandflat at the beginning of each run. The control sediment was sieved ( $0.5 \mathrm{~mm}$ mesh) and frozen to defaunate it, and then thawed and thoroughly washed with seawater. This sediment was predominantly comprised of medium, coarse and fine sand (Table 1).

Juvenile Macomona liliana were collected by sieving surface sandflat Wairoa Island sediments in seawater ( $0.5 \mathrm{~mm}$ mesh); the material retained on the sieve was returned to the laboratory and individuals $<3 \mathrm{~mm}$ (shell length) were sorted under a stereomicroscope. The bivalves were kept in filtered, aerated seawater under the same temperature and light regime as the experiments conducted (see below), and were used in the experiments within $3 \mathrm{~d}$ of collection.

Setup. Experiments were conducted in rectangular aquaria $\left(78 \times 9 \times 10 \mathrm{~cm} ; 522 \mathrm{~cm}^{2}\right.$ working surface area), with recirculating seawater, under constant temperature and $24 \mathrm{~h}$ dim light. Seawater flow in the working area of the aquaria was $\sim 2 \mathrm{~cm} \mathrm{~s}^{-1}$. A bilge pump (Johnson 32-1015-01) pumped seawater into each aquarium from separate 151 reservoirs through a silicon tube. To dissipate turbulence generated by the in-flowing water, a baffle and a straw array were inserted at 10 and $13 \mathrm{~cm}$, respectively, from the upstream end of each aquarium. The baffle consisted of a plate with numer-

Table 1. Grain size composition (\% volume) of the terrestrial (TS) and control sediments used during the experiments. Composition was determined using a Galai particle analyser (Galai Cis-100; Galai Productions). Classifications follow the Wentworth scale

\begin{tabular}{|lcccccc|}
\hline TS / sediment & $\begin{array}{c}\text { Clay } \\
(<3.9 \mu \mathrm{m})\end{array}$ & $\begin{array}{c}\text { Silt } \\
(3.9-62.5 \mu \mathrm{m})\end{array}$ & $\begin{array}{c}\text { Fine sand } \\
(62.5-500 \mu \mathrm{m})\end{array}$ & $\begin{array}{c}\text { Medium sand } \\
(250-500 \mu \mathrm{m})\end{array}$ & $\begin{array}{c}\text { Coarse sand } \\
(500-2000 \mu \mathrm{m})\end{array}$ & $\begin{array}{c}\text { Gravel/shell hash } \\
(>2000 \mu \mathrm{m})\end{array}$ \\
\hline 0 d TS (run A) & 0.24 & 12.90 & 80.24 & 3.42 & 2.24 & 0.96 \\
7 d TS (run B) & 0.15 & 8.55 & 79.86 & 7.06 & 3.98 & 0.40 \\
14 d TS (run C) & 0.29 & 15.10 & 78.33 & 37.14 & 32.91 & 0.91 \\
Control sediment & 0.00 & 0.56 & 20.20 & 3.20 & 9.21 \\
\hline
\end{tabular}


ous small holes $(0.5 \mathrm{~cm}$ diameter), and the straw array $(7 \mathrm{~cm}$ high $\times 7 \mathrm{~cm}$ long) was comprised of $0.5 \mathrm{~cm}$ diameter straws. Water travelled past the baffle, through the straw array, over the sediment, and then left the aquaria by gravity through a horizontal row of holes along the upper edge of the aquaria end walls. Water depth in the aquaria was $\sim 9 \mathrm{~cm}$. Seawater temperature and conductivity were monitored in one aquarium throughout the experiments, using a PortaMess 913 (Knick) and a conductivity sensor (SE204, Knick), respectively. The temperature of the seawater was $14.5 \pm$ $0.2^{\circ} \mathrm{C}$, and the conductivity was $41.7 \pm 0.5 \mathrm{mS}$ (means \pm SDs, $\mathrm{n}=9$ ).

Protocol. Sediment was added to each of 4 aquaria to a depth of $3 \mathrm{~cm}$, and the aquaria were filled with seawater, which was then kept aerated using aquarium pumps. After 6 to $8 \mathrm{~h}$, the aerators were removed, flow was initiated, and a TS suspension was added to those aquaria requiring a TS treatment. To do so, aliquots of $40 \mathrm{~cm}^{3}$ of TS were mixed with seawater to make the sediment liquid enough to pour. This mixture was then slowly added to the aquaria upstream of the baffles and straw arrays. The TS gradually and evenly settled on the surface of the sediment over time. The aquaria were then left overnight $(14 \mathrm{~h})$. This resulted in TS-surface deposits ranging from 0.5 to $1.7 \mathrm{~mm}$ thick over the experiment (derived from microelectrode measurements; see below; Table 2). The next morning, the flow was stopped, seawater in the aquaria and reservoirs was changed (taking care not to disturb the TS deposits), and the flows were reinstated. A thin layer of control sediment was then added to the surfaces of the sediment in those aquaria requiring a TSburied treatment: aliquots of $40 \mathrm{~cm}^{3}$ of sediment were mixed with seawater and added at the water surfaces along the length of the working area of the aquaria, allowing the sediment to settle through the water columns to the aquarium floors. It was not possible to add this heavier sediment to the aquaria using the same methodology as that used to add the TS suspensions. Our rationale for adding the TS to the flumes in this way was based on our observations of how this occurs in the field situation. TS commonly enters an estuary in suspension after being mixed with seawater, and settles on the seafloor once tides/currents have subsided (Cummings et al. 2003).

Table 2. Thickness (mm) of the terrestrial sediment (TS) layer of replicate TS-surface treatments

\begin{tabular}{|lccccc|}
\hline Run (TS age) & 1 & 2 & 3 & 4 & Mean \pm SD \\
\hline A $(0 \mathrm{~d})$ & 1.0 & 0.8 & 1.1 & 1.7 & $1.15 \pm 0.39$ \\
B $(7 \mathrm{~d})$ & 0.8 & 1.5 & 1.4 & 0.6 & $1.08 \pm 0.44$ \\
C $(14 \mathrm{~d})$ & 1.1 & 0.5 & 1.0 & 1.1 & $0.93 \pm 0.29$ \\
\hline
\end{tabular}

One hour later, 50 Macomona liliana juveniles were added to each aquarium by introducing them just below the water surface using a pipette and allowing them to drift to the sediment surface. Due to the time required to measure microprofiles of porewater solute concentrations, microelectrode measurements could be made in only 4 aquaria on a single day; thus, 1 to 2 replicates of each of the 3 treatments were run each day, and each run was completed over $3 \mathrm{~d}$.

Preliminary measurements. To estimate the incubation time needed to establish 'steady state' conditions in the TS treatments, time series of $\left[\mathrm{O}_{2}\right], \mathrm{pH}$ and apparent $\mathrm{H}_{2}$ diffusivity were simultaneously measured over a period of 80 min starting at 6 min before the addition of a $0 \mathrm{~d}$ TS suspension to one aquarium containing $3 \mathrm{~cm}$ of control sediment. Three sensors were positioned at 0.1 to $0.2 \mathrm{~mm}$ above the surface of the control sediment: a needle-type, fiber-optic $\mathrm{O}_{2}$ microsensor (Precision Sensing; tip diameter $<0.05 \mathrm{~mm}, 90 \%$ response time $<0.5 \mathrm{~s}$ ), a $\mathrm{pH}$ microelectrode (Unisense; tip diameter: $0.05 \mathrm{~mm}$ ) and a diffusivity microelectrode (Unisense; tip diameter: $0.1 \mathrm{~mm}$; Revsbech et al. 1998). In addition to the time-series measurements, one vertical $\mathrm{O}_{2}$ profile and one $\mathrm{pH}$ profile were measured before and $2 \mathrm{~h}$ after the addition of the TS suspension.

Behavioural observations of Macomona liliana. To determine the burrowing response of post-settlement Macomona liliana juveniles to the treatments, the number of individuals that remained on the sediment surface (i.e. had not buried) after 1, 2 and $4 \mathrm{~h}$ was recorded. Once they had buried, it was evident from movement traces on the sediment surface that the juveniles were crawling below the sediment surface; this was noted in all treatments.

Microprofiles. One $\left[\mathrm{O}_{2}\right]$ profile, one $\mathrm{pH}$ profile, and 2 profiles of apparent $\mathrm{H}_{2}$ diffusivity were measured, normal to the sediment surface and across the sediment-water interface, in each replicate aquarium at a resolution of $0.1 \mathrm{~mm} . \mathrm{O}_{2}$ was measured with a Clarktype microelectrode, with an internal reference and a guard cathode (tip diameter: $0.05 \mathrm{~mm}$, stirring sensitivity $<1 \%, 90 \%$ response time $<1$ s) (Revsbech 1989). $\mathrm{pH}$ and the apparent $\mathrm{H}_{2}$ diffusivity [the product of sediment porosity $(\phi)$ and the effective $\mathrm{H}_{2}$ diffusion coefficient $\left.\left(D_{\mathrm{S}}\right)\right]$ were measured as described above. Measurement of the apparent $\mathrm{H}_{2}$ diffusivity was based on the diffusion of $\mathrm{H}_{2}$ from an internal sensor reservoir, through an internal diffusion barrier positioned within the sensor tip, and out into the surrounding porewater of the sediment (Revsbech et al. 1998). The $\left[\mathrm{H}_{2}\right]$ at the tip of the sensor was then a function of the apparent diffusivity in the medium. The internal reservoir was continuously flushed with $\mathrm{H}_{2}$ at a constant flow rate.

To measure profiles, one $\mathrm{O}_{2}$ and one apparent diffusivity microelectrode were mounted on a motorized 
micromanipulator that was attached to a stand. The 2 electrodes were positioned at the sediment surface, and were arranged in a line perpendicular to the direction of seawater flow. The tips were aligned with each other using the seawater surface as a reference. After one profile was completed with each microelectrode, the $\mathrm{O}_{2}$ microelectrode was replaced with a $\mathrm{pH}$ microelectrode, the tip of the $\mathrm{pH}$ microelectrode was aligned with the tip of the apparent diffusivity microelectrode as described above, and one profile was again measured with each electrode. The PC Windows program Profix (Unisense) controlled the stepwise movement of the micromanipulator via a motor controller, and read the data automatically from the microsensor amplifiers via an A/D converter (ADC-101, Pico Technology) connected to the parallel port of a laptop PC.

All microelectrodes were calibrated once a day at the experimental temperature. The apparent diffusivity microelectrode was calibrated by measuring the electrode current in 2 media of known diffusivity: 0.04-0.06 mm glass beads and the overlying static seawater. The reference value for the diffusivity of $\mathrm{H}_{2}$ in static seawater was calculated from the diffusivity of $\mathrm{O}_{2}$ (Broecker \& Peng 1974) corrected for temperature according to Yuan-Hui \& Gregory (1974). The apparent diffusivity in glass beads was taken from Revsbech et al. (1998). The $\mathrm{O}_{2}$ microelectrode and the fiber-optic microsensor were calibrated in $100 \%$ air-saturated seawater and in seawater that had been deoxygenated with sodium sulfite. Standard buffers were used to calibrate the $\mathrm{pH}$ microelectrode.

Data analysis. The relative positions of the surfaces of the control sediment and the upper and lower boundary of the surface deposit of TS along a vertical scale were identified by distinct changes in the slope of the $\left[\mathrm{O}_{2}\right]$ profiles. Such changes resulted from differences in the solute diffusivity in free seawater and in the 2 types of sediment. The top of the diffusive boundary layer (DBL) (i.e. the boundary between the freeflowing water and the diffusive boundary layer) was determined as the intersection between the extrapolated linear $\left[\mathrm{O}_{2}\right]$ gradient in the DBL and the constant $\left[\mathrm{O}_{2}\right]$ of the overlying mixed seawater (Jørgensen \& Des Marais 1990).

The average apparent diffusivities $\left(\Delta D_{\mathrm{S}}\right)$ of the control sediment and the surface and subsurface TS deposits were estimated by averaging data points along the profiles through the deposits or control sediment. To account for the spatial resolution of the diffusivity microelectrode, data points measured within $0.2 \mathrm{~mm}$ of the interfaces between seawater, control sediment and TSwere excluded from this calculation (for details, see Revsbech et al. 1998).

The $\mathrm{O}_{2}$ consumptions of the sediment treatments were estimated in 2 ways, i.e. using both the mea- sured porewater $\left[\mathrm{O}_{2}\right]$ profiles and the profiles measured across the DBL above the sediment surface. The profiles across the DBL were used to estimate the rate of the diffusive $\mathrm{O}_{2}$ uptake (DOU) following Jørgensen \& Revsbech (1985) and Rasmussen \& Jørgensen (1992). The sediment $\left[\mathrm{O}_{2}\right]$ profiles were used to model the depth-integrated $\mathrm{O}_{2}$ consumption rates $(R)$ and a depth profile of the $\mathrm{O}_{2}$ consumption following Berg et al. (1998). To do so, measured diffusivities of the 2 different sediment types (terrestrial and control sediment) and the depths of their interfaces were required. $\mathrm{O}_{2}$ profiles measured in the TS-buried treatment did not allow detection of this interface. Consequently, no depth-integrated $\mathrm{O}_{2}$ consumption and no $\mathrm{O}_{2}$ consumption profiles were computed, i.e. the $\mathrm{O}_{2}$ consumption of the TS-buried treatment was calculated only from $\left[\mathrm{O}_{2}\right]$ profiles in the DBL.

The significance of the differences in apparent diffusivity, bottom water $\mathrm{pH}$ and the change in porewater $\mathrm{pH}(\Delta \mathrm{pH})$ among treatments (i.e. control, TS-surface, TS-buried) were assessed separately for each run using ANOVA (PROC GLM, SAS Institute 1999). Differences among treatments in the numbers of Macomona liliana individuals that did not burrow over time (i.e. 1, 2 and $4 \mathrm{~h}$ after addition) were also tested separately for each run using repeated measures ANOVA (PROC GLM, SAS Institute 1999). When time $\times$ treatment interaction terms were significant, the analyses were conducted separately for each time. Actual differences between treatments were determined using Tukey's tests. Prior to the ANOVAs, the normality and homogeneity of variances of the data were assessed using Shapiro-Wilks and F-max tests, respectively, and data were rank transformed if required. To determine whether the effect of the TS-surface treatment on the DOU differed with 'age' of the TS, the change in DOU versus the thickness of the deposit was plotted separately for each TS age/run, and the slope of the linear regression through each set of data points was calculated. The significance of the differences in slopes among runs was assessed using ANCOVA (PROC GLM, SAS).

\section{RESULTS}

\section{Preliminary measurements}

Measurements of $\left[\mathrm{O}_{2}\right]$ made in one aquarium prior to the addition of TS revealed an effective DBL thickness of $\sim 0.4 \mathrm{~mm}$ (Fig. 1A, hollow circles). $\mathrm{O}_{2}$ penetrated the sediment down to $0.9 \mathrm{~mm}$, and the $\mathrm{pH}$ declined from 8.02 in the bottom water, to a minimum of 7.47 in the sediment porewater at $0.6 \mathrm{~mm}$ depth (Fig. 1B). Addition of $0 \mathrm{~d}$ TS to this aquarium resulted 

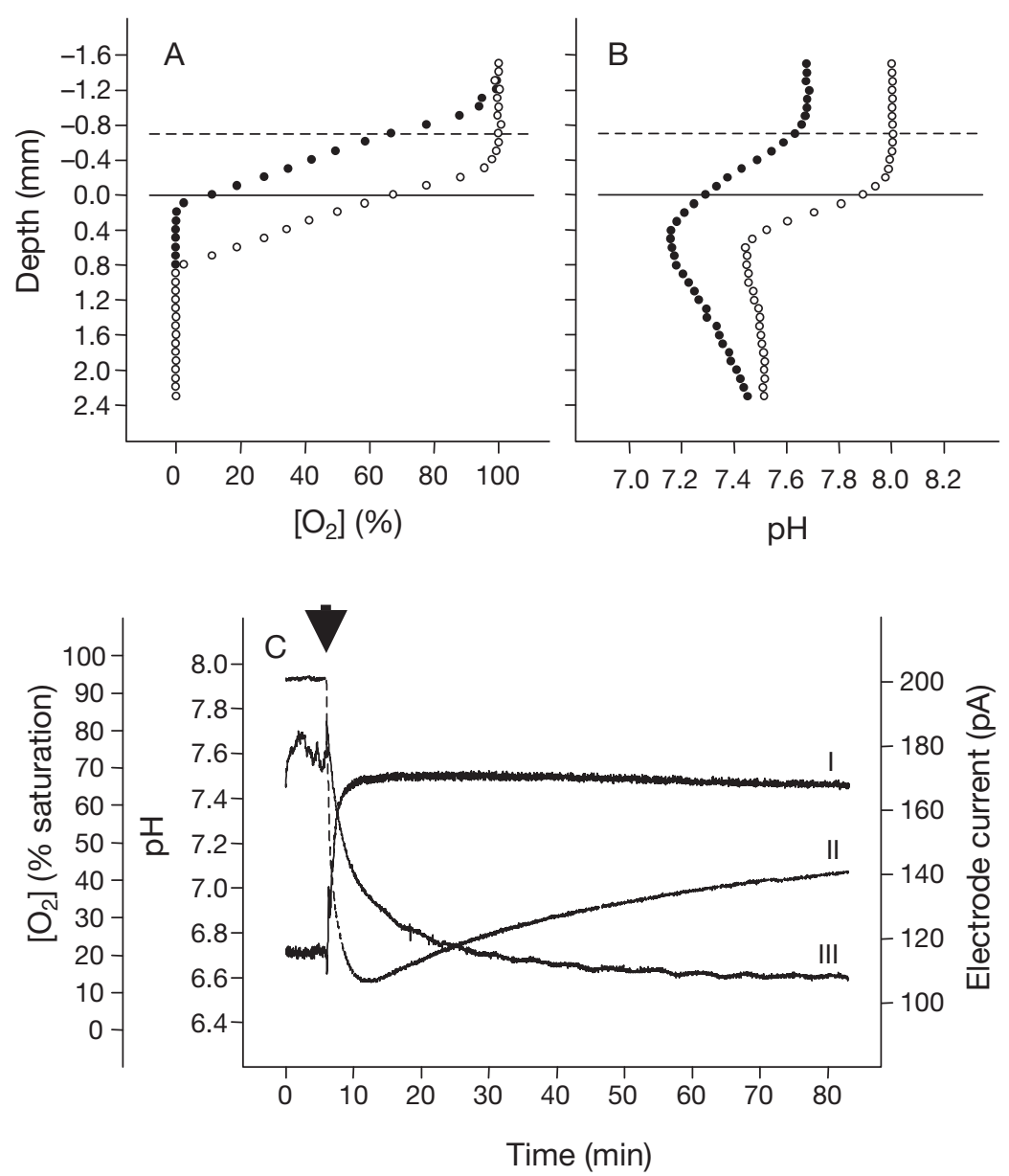

Fig. 1. Vertical profiles of (A) $\left[\mathrm{O}_{2}\right]$ and (B) $\mathrm{pH}$ recorded 10 min before (O) and $2 \mathrm{~h}$ after (•) a $40 \mathrm{~cm}^{3} 0 \mathrm{~d}$ terrestrial sediment (TS) suspension was added to an aquarium containing control sediment. The TS-seawater interface (---) is located $0.7 \mathrm{~mm}$ above the original sediment surface (-). (C) Simultaneous time-series measurements of $\left[\mathrm{O}_{2}\right]$ (curve III), $\mathrm{pH}$ (curve II), and $\mathrm{H}_{2}$ diffusion (curve I) in the diffusive boundary layer 0.1 to $0.2 \mathrm{~mm}$ above the sediment surface. The TS suspension was added to the aquarium 6 min after the recording began (arrow)

in an elevation of the sediment surface by $0.7 \mathrm{~mm}$. Consequently, the tips of the microelectrodes that were initially positioned in the DBL at 0.1 to $0.2 \mathrm{~mm}$ above the sediment surface became buried in the deposit as sedimentation progressed. The signal of the $\mathrm{H}_{2}$ electrode was initially low, but had increased to a high and constant value (Fig. 1C) by only $\sim 10$ min after TS addition, indicating a rapid initial deposition and no subsequent gradual compaction of the surface layer. $\left[\mathrm{O}_{2}\right]$ decreased from $\sim 75$ to $37 \%$ saturation within 5 min of TS addition, and continued to decrease slowly as the TS layer built up (Fig. 1C). In contrast, the $\mathrm{pH}$ decreased from 7.94 to a minimum of 6.58 within $5 \mathrm{~min}$ and increased slowly thereafter (Fig. 1C). Two hours after TS addition, the $\mathrm{O}_{2}$ penetration depth measured from the surface of the TS layer was $1.0 \mathrm{~mm}$ (Fig. 1A, solid circles). As the surficial TS deposit was $0.7 \mathrm{~mm}$ thick, $\mathrm{O}_{2}$ had penetrated only $0.3 \mathrm{~mm}$ into the underlying control sediment. Also after $2 \mathrm{~h}$, the $\mathrm{pH}$ of the bottom water and the minimum $\mathrm{pH}$ in the sediment porewater had decreased by $\sim 0.3$ (Fig. 1B).

\section{Apparent gas diffusivities}

The average apparent diffusivities of the control sediments were similar in all runs $\left(0.62 \times 10^{-5}\right.$ to $0.64 \times 10^{-5} \mathrm{~cm}^{2}$ $\mathrm{s}^{-1}$; Table 3). Diffusivities of the surface TS deposit ranged from $1.07 \times$ $10^{-5}$ to $1.19 \times 10^{-5} \mathrm{~cm}^{2} \mathrm{~s}^{-1}$ throughout the experiment, and were significantly higher than those of the control sediment in all runs (Table 4). Inspection of the microprofiles of apparent diffusivity measured in the TSburied treatment revealed no distinct changes in $\mathrm{H}_{2}$ diffusivity along the profile through the surface layer of the control sediment, the TS deposit, and the underlying sediment, but rather a gradual increase in diffusivity with depth. The particles of the control sediment partially sank into the surface deposit of TS so that the uppermost sediment was comprised of particles of control sediment mixed with TS. To estimate the diffusivity of this mixed layer, we averaged data points along the profiles down to the depth at which the apparent diffusivity approached that of the control sediment. These estimates were slightly higher $(0.66 \times$ $10^{-5}$ to $0.72 \times 10^{-5} \mathrm{~cm}^{2} \mathrm{~s}^{-1}$ ), but were significantly different from those of the control treatment only in run B (Table 4).

\section{$\mathrm{O}_{2}$ penetration, DOU, $R$ and $\mathrm{O}_{2}$ consumption profiles}

$$
\mathrm{O}_{2} \text { penetration depth }
$$

The average $\mathrm{O}_{2}$ penetration depth, calculated over all 12 replicates for each treatment, was lowest in the control sediment treatment $(0.70 \pm 0.13 \mathrm{~mm})$ and highest in the TS-surface treatment $(1.35 \pm 0.28 \mathrm{~mm})$. In the TS-buried treatment, $\mathrm{O}_{2}$ penetrated down to $0.90 \pm$ $0.16 \mathrm{~mm}$. 
Table 3. Apparent diffusivity $\left(\phi D_{\mathrm{S}}\right)$ of control sediment (control, 0.3 to $5 \mathrm{~mm}$ depth), surface terrestrial sediment (TS) deposit (TSsurface), and buried TS deposit (TS-buried, 0.3 to $1.3 \mathrm{~mm}$ depth); average $\mathrm{pH}$ of the bottom seawater in runs and treatments $(\mathrm{n}=$ 4); and magnitude of drop in $\mathrm{pH}(\Delta \mathrm{pH})$ along a vertical profile measured from a position above the diffusive boundary layer to $4 \mathrm{~mm}$ deep in the control sediment. Values are means \pm SDs

\begin{tabular}{|lccc|}
\hline Treatment & $\begin{array}{c}\phi D_{\mathrm{S}} \\
\left(\times 10^{-5} \mathrm{~cm}^{2} \mathrm{~s}^{-1}\right)\end{array}$ & $\begin{array}{c}\text { Bottom } \\
\text { seawater } \\
\mathrm{pH}\end{array}$ & $\begin{array}{c}\text { Pore } \\
\text { seawater } \\
\Delta \mathrm{pH}\end{array}$ \\
\hline Run A (0 d) & & & \\
Control & $0.64 \pm 0.06$ & $7.62 \pm 0.04$ & $0.59 \pm 0.01$ \\
TS-buried & $0.72 \pm 0.16$ & $7.62 \pm 0.10$ & $0.67 \pm 0.06$ \\
TS-surface & $1.07 \pm 0.04$ & $7.49 \pm 0.04$ & $0.74 \pm 0.06$ \\
Run B (7 d) & & & \\
Control & $0.62 \pm 0.02$ & $7.69 \pm 0.07$ & $0.77 \pm 0.02$ \\
TS-buried & $0.68 \pm 0.01$ & $7.59 \pm 0.06$ & $0.91 \pm 0.10$ \\
TS-surface & $1.16 \pm 0.03$ & $7.66 \pm 0.10$ & $0.85 \pm 0.10$ \\
Run C (14 d) & & & \\
Control & $0.64 \pm 0.03$ & $7.65 \pm 0.03$ & $0.73 \pm 0.05$ \\
TS-buried & $0.66 \pm 0.07$ & $7.63 \pm 0.05$ & $0.71 \pm 0.08$ \\
TS-surface & $1.19 \pm 0.04$ & $7.67 \pm 0.05$ & $0.72 \pm 0.07$ \\
\hline
\end{tabular}

\section{DOU and $R$}

The average DOU of the control sediment $\left(\mathrm{DOU}_{\mathrm{C}}\right)$, estimated from the slopes of the average $\left[\mathrm{O}_{2}\right]$ profiles in the DBL of runs A to C, was $1605 \mu \mathrm{mol} \mathrm{m}{ }^{-2} \mathrm{~h}^{-1}$ (Table 5). The average DOU of the TS-surface treatment $\left(\mathrm{DOU}_{\text {surf }}\right)$ was similar $\left(1501 \mu \mathrm{mol} \mathrm{m} \mathrm{m}^{-2} \mathrm{~h}^{-1}\right)$, while that of the TS-buried treatments $\left(\mathrm{DOU}_{\mathrm{sub}}\right)$ was lower $\left(1176 \mu \mathrm{mol} \mathrm{m} \mathrm{m}^{-2} \mathrm{~h}^{-1}\right)$. Modeling of the 12 porewater $\left[\mathrm{O}_{2}\right]$ profiles measured in the control and the TS-surface treatments revealed average depth-integrated $R$ that were $\sim 20$ and $\sim 50 \%$ lower than the respective averages for DOU. The relationship between the change in $R$ and the thickness of the TS-surface deposit revealed by linear regression showed that a surface layer of $0 \mathrm{~d}$ TS (run A) reduced the total depth-integrated $\mathrm{O}_{2}$ consumption of the sediment (incl. the TS-surface deposit) by $643 \mu \mathrm{mol} \mathrm{m} \mathrm{m}^{-2} \mathrm{~h}^{-1} \mathrm{~mm}^{-1}$ relative to control sediments, whereas 7 and $14 \mathrm{~d}$ old TS-surface deposits reduced $R$ by only 397 and $487 \mu \mathrm{mol} \mathrm{m} \mathrm{m}^{-2} \mathrm{~h}^{-1} \mathrm{~mm}^{-1}$, respectively (Table 6; $\mathrm{p}=0.0055$, ANCOVA).

Table 4. Results of ANOVA to investigate differences in apparent diffusivity, bottom water $\mathrm{pH}$, and change in pore seawater $\mathrm{pH}$ among treatments of a particular run. Multiple comparisons: Duncan's tests; TS-surface: surface terrestrial sediment, TS-buried: buried terrestrial sediment, and C: control sediment treatments. Trt: treatment; ns: not significantly different $(p>0.05)$

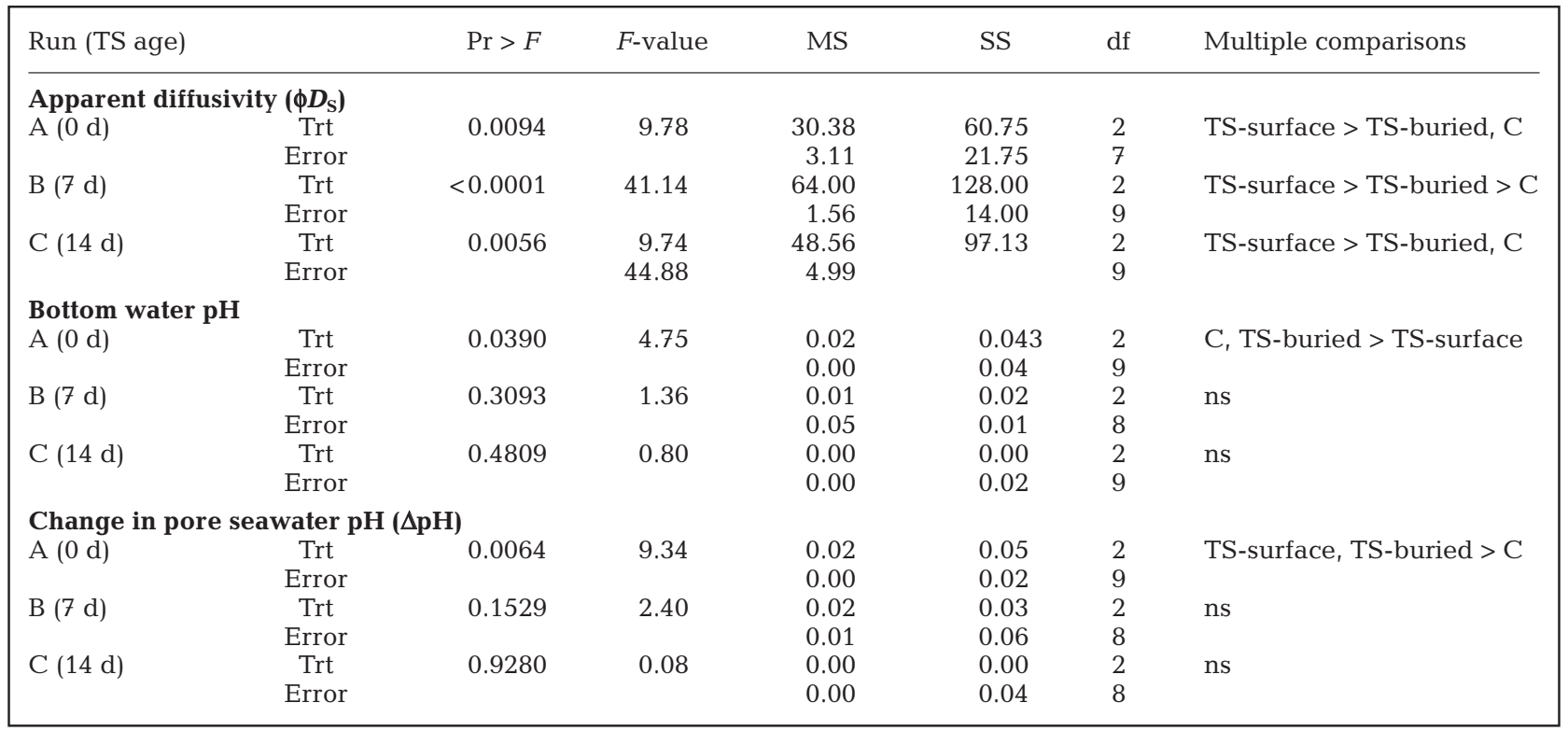

Table 5. Diffusive oxygen uptake (DOU $\left.\pm \mathrm{SD}, \mu \mathrm{mol} \mathrm{m} \mathrm{m}^{-2} \mathrm{~h}^{-1}\right)$ and/or depth-integrated $\mathrm{O}_{2}$ consumption $\left(R \pm \mathrm{SD}, \mu \mathrm{mol} \mathrm{m}{ }^{-2} \mathrm{~h}^{-1}\right)$ of control sediment (DOU-control, $R$-control), TS-surface treatments (DOU-surface, $R$-surface), and TS-buried treatments (DOUburied). DOU was calculated from the $\left[\mathrm{O}_{2}\right]$ gradient in the diffusive boundary layer. $R$ was estimated from porewater $\left[\mathrm{O}_{2}\right]$ profiles

\begin{tabular}{|lcccrr|r|}
\hline Run (TS age) & DOU-control & $R$-control & DOU-surface & $R$-surface & DOU-buried \\
\hline A $(0 \mathrm{~d})(\mathrm{n}=4)$ & $1613 \pm 318$ & $1365 \pm 93$ & $1630 \pm 481$ & $739 \pm 180$ & $954 \pm 148$ \\
B $(7 \mathrm{~d})(\mathrm{n}=4)$ & $1619 \pm 549$ & $1062 \pm 254$ & $1324 \pm 402$ & $854 \pm 166$ & $1465 \pm 124$ \\
C $(14 \mathrm{~d})(\mathrm{n}=4)$ & $1564 \pm 429$ & $1369 \pm 667$ & $1548 \pm 529$ & $793 \pm 169$ & $1108 \pm 336$ \\
Overall $(\mathrm{n}=12)$ & $1605 \pm 401$ & $1292 \pm 388$ & $1501 \pm 449$ & $796 \pm 156$ & $1176 \pm 302$ \\
\hline
\end{tabular}


Table 6. Reduction in depth-integrated $\mathrm{O}_{2}$ consumption ( $\Delta R$-surface) caused by a $1 \mathrm{~mm}$ thick surface terrestrial sediment (TS) deposit relative to the control sediment, and the contributions of the surface TS deposit and the underlying sediment to the total depth-integrated $\mathrm{O}_{2}$ consumption ( $R$-surface, mean $\pm \mathrm{SD}, \mathrm{n}=4)$. Values for $\Delta R$-surface were derived using the slope of the linear regression of measurements from surface TS and control sediment treatments

\begin{tabular}{|c|c|c|c|c|}
\hline \multirow{2}{*}{$\begin{array}{l}\text { Run } \\
\text { (TS age) }\end{array}$} & \multirow{2}{*}{$\begin{array}{c}\Delta R \text {-surface } \\
\left(\mu \mathrm{mol} \mathrm{m}^{-2}\right. \\
\left.\mathrm{h}^{-1} \mathrm{~mm}^{-1}\right)\end{array}$} & \multirow[t]{2}{*}{$\mathrm{R}^{2}$} & \multicolumn{2}{|c|}{$R$-surface $\left(\mu \mathrm{mol} \mathrm{m} \mathrm{m}^{-2} \mathrm{~h}^{-1}\right)$} \\
\hline & & & $\begin{array}{c}\text { Surface TS } \\
\text { deposit }\end{array}$ & $\begin{array}{c}\text { Underlying } \\
\text { control } \\
\text { sediment }\end{array}$ \\
\hline$A(0 d)$ & 643 & 0.974 & $137 \pm 90$ & $467 \pm 160$ \\
\hline $\mathrm{B}(7 \mathrm{~d})$ & 397 & 0.978 & $252 \pm 88$ & $602 \pm 105$ \\
\hline$C(14 \mathrm{~d})$ & 487 & 0.940 & $121 \pm 119$ & $672 \pm 210$ \\
\hline
\end{tabular}

\section{$\mathrm{O}_{2}$ consumption profile}

In the control sediment, $\mathrm{O}_{2}$ consumption was highest just beneath the sediment-water interface (Fig. 2). In contrast, $\mathrm{O}_{2}$ consumption peaked at the boundary between the oxic and the anoxic layer in the TSsurface treatments (see Fig. 3 for example profiles). Depending on the thickness of the surface TS deposit, this boundary was positioned near the surface of the deposit-underlying sediment or at some depth in this sediment. The average depth-integrated $\mathrm{O}_{2}$ consumption of the sediment underlying a TS-surface deposit increased with age of the TS (Table 6). The depth-integrated $\mathrm{O}_{2}$ consumption of the TS-surface layer itself was highest in the $7 \mathrm{~d}$ TS (run B) and lowest in the $14 \mathrm{~d}$ TS (run $\mathrm{C}$, Table 6). The $\mathrm{O}_{2}$ profiles measured in the $\mathrm{TS}_{\text {sub }}$ treatment (Fig. 4) did not allow detection of the interfaces between the 2 sediment types, terrestrial sediment and control sediment.

\section{pH}

The $\mathrm{pH}$ of the aquarium bottom water was very similar in all treatments and runs (i.e. average $\mathrm{pH}_{\mathrm{bw}}$ > 7.59), although it was slightly lower in the $0 \mathrm{~d}$ TS-surface treatment than in the remaining treatments of run $\mathrm{A}$ (average: 7.49, Table $3 ; \mathrm{p}=0.0390$, Table 4). Table 3 shows the magnitude of change in $\mathrm{pH}(\Delta \mathrm{pH})$ across the DBL to $4 \mathrm{~mm}$ deep in the underlying control sediment per treatment per run. In the control sediment treatments, pH decreased by maximally $0.59 \pm 0.01$ in run A, $0.77 \pm 0.02$ in run $B$, and $0.73 \pm 0.05$ in run C. Significant differences in $\Delta \mathrm{pH}$ between treatments were detected only in run $\mathrm{A}$, where the magnitude of the decrease was larger in the TS-surface and TS-buried treatments than in the control treatment (Table $3 ; \mathrm{p}=$

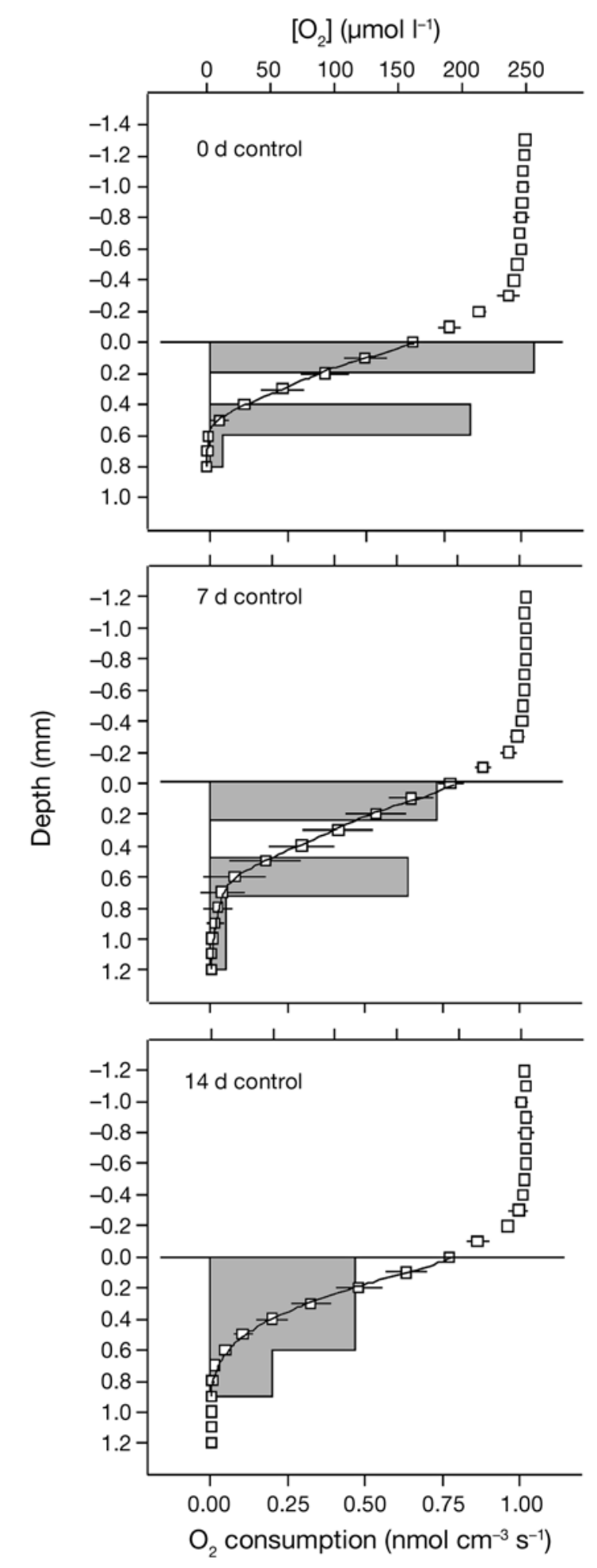

Fig. 2. Examples of vertical $\left[\mathrm{O}_{2}\right](\square)$ and $\mathrm{O}_{2}$ consumption (bars) profiles through the sediment-water interface of the control treatment (means $\pm \mathrm{SD}, \mathrm{n}=4$ ) for each experimental run. $\mathrm{O}_{2}$ consumption profiles and fits $\left(\mathrm{R}^{2}>0.9991\right)$ were modeled as described by Berg et al. (1998). (-) Sediment surface. Concentrations are given per volume of porewater, but consumption rates are given per volume of sediment 


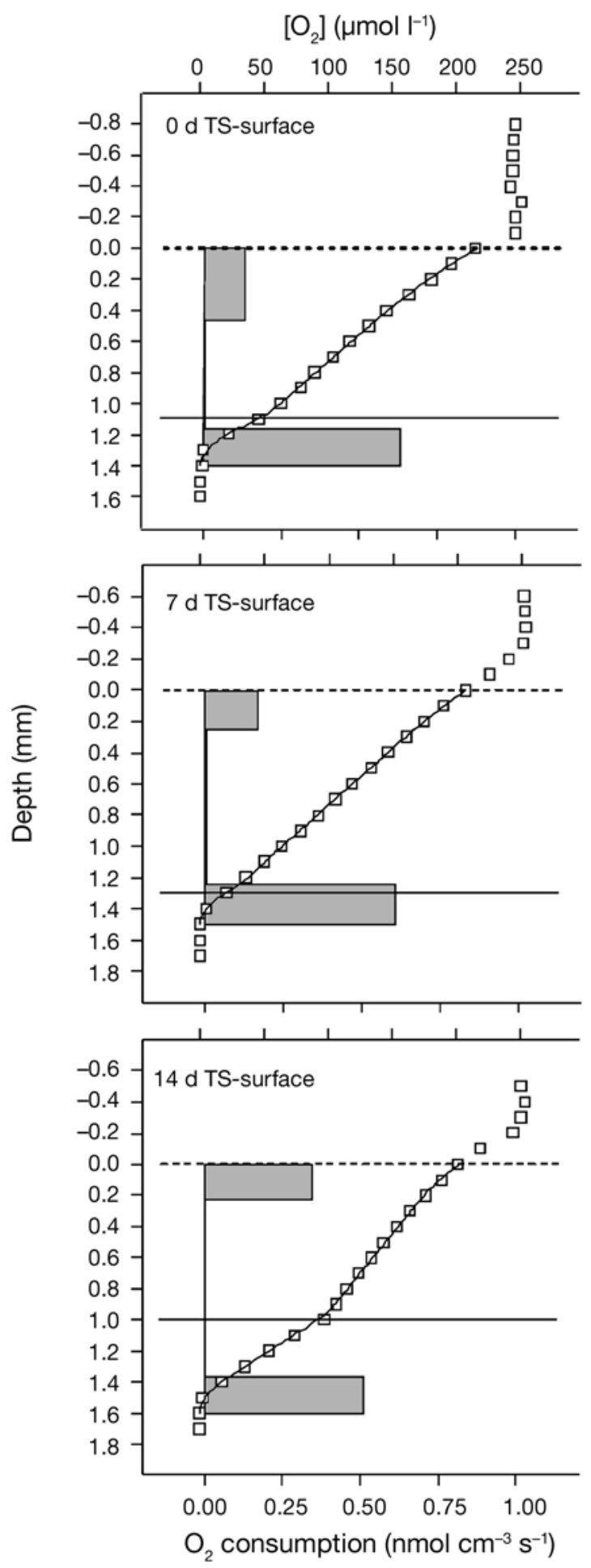

Fig. 3. Examples of vertical $\left[\mathrm{O}_{2}\right](\square)$ and $\mathrm{O}_{2}$ consumption (bars) profiles through the sediment-water interface of the TS-surface treatment for each experimental run. $\mathrm{O}_{2}$ consumption profiles and fits $\left(\mathrm{R}^{2}>0.9991\right)$ were modeled as described by Berg et al. (1998). (—) Interface between the TS-surface deposit and the underlying sediment, (-----) TS surface. Concentrations are given per volume of porewater, but consumption rates are given per volume of sediment

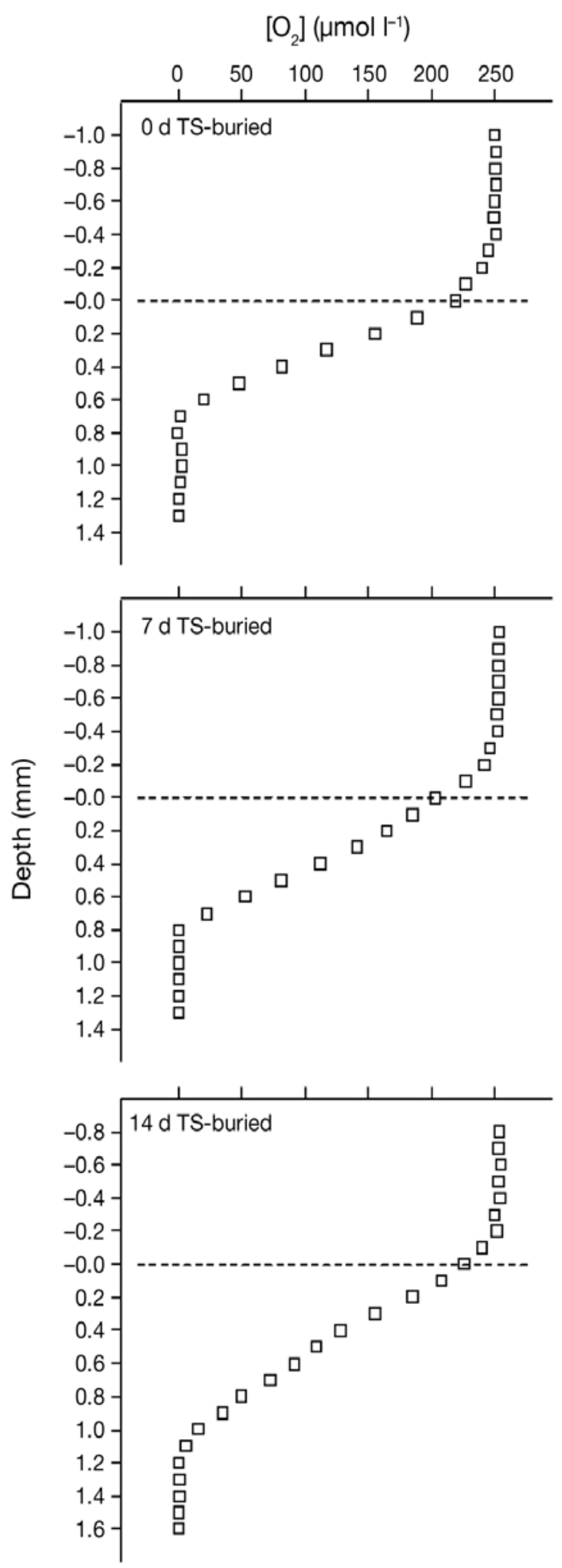

Fig. 4. Examples of vertical $\left[\mathrm{O}_{2}\right]$ profiles $(\square)$ through the sediment-water interface of the TS-buried treatment for each experimental run. (---) Surface of the TS-buried treatment. Concentrations are given per volume of porewater 
0.0064, Table 4). In the TS-surface treatment, the $\mathrm{pH}$ shift $\left(\Delta \mathrm{pH}_{\text {surf-C }}\right)$ decreased with increasing TS age (i.e. $0.15 \pm 0.05,0.09 \pm 0.08$, and $-0.03 \pm 0.10$ in runs $A$ to $C$, respectively) (Table 3 ). In the TS-buried treatment, the $\mathrm{pH}$ shift $\left(\Delta \mathrm{pH}_{\text {sub-C}}\right)$ was highest in run $\mathrm{B}$ and lowest in run $C$ (i.e. $0.08 \pm 0.06,0.13 \pm 0.08$, and $0.02 \pm 0.02$ in runs $\mathrm{A}$ to $\mathrm{C}$, respectively). Interestingly, the $\mathrm{pH}$ shift in the TS-surface treatment was highly correlated with apparent diffusivity (i.e. $\mathrm{R}=-0.891$ ); such a strong correlation was not observed in the TS-buried treatment (i.e. $\mathrm{R}=0.376$ ).

\section{Behaviour of Macomona liliana}

Burial of Macomona liliana juveniles was high throughout the experiment irrespective of treatment (>70\%; Fig. 5). However, significant negative effects of surface TS deposits were detected in runs A and B (Table 7). Significantly fewer individuals had buried in the TS-surface than in the control treatments 1,2 and $4 \mathrm{~h}$ after their addition to the aquaria with 0 and $7 \mathrm{~d}$ TS-surface sediments (Table 7). For the $0 \mathrm{~d}$ TSsurface treatment, these differences equate to an average of 6 to 7 more individuals (or 10.5 to $13.5 \%$ of the total number added; Fig. 5) that had not buried into the sediment. For the $7 \mathrm{~d}$ TS-surface treatment, this difference was slightly higher, at 6 to 10 ind. (11.6 to $20 \%$ of those added). Although the burrowing response of Macomona in the TSburied treatments was always intermediate between that in the TS-surface and control treatments (Fig. 5), there was no statistically significant effect of the TSburied treatment of any age on burrowing (Table 7). Similarly, no burrowing differences were detected between any of the treatments of run $\mathrm{C}$ (Fig. 5, Table 7).

\section{DISCUSSION}

This study has demonstrated that millimeter-thin surface deposits of terrigenous sediments affect both the chemistry of the sediment-water interface and the

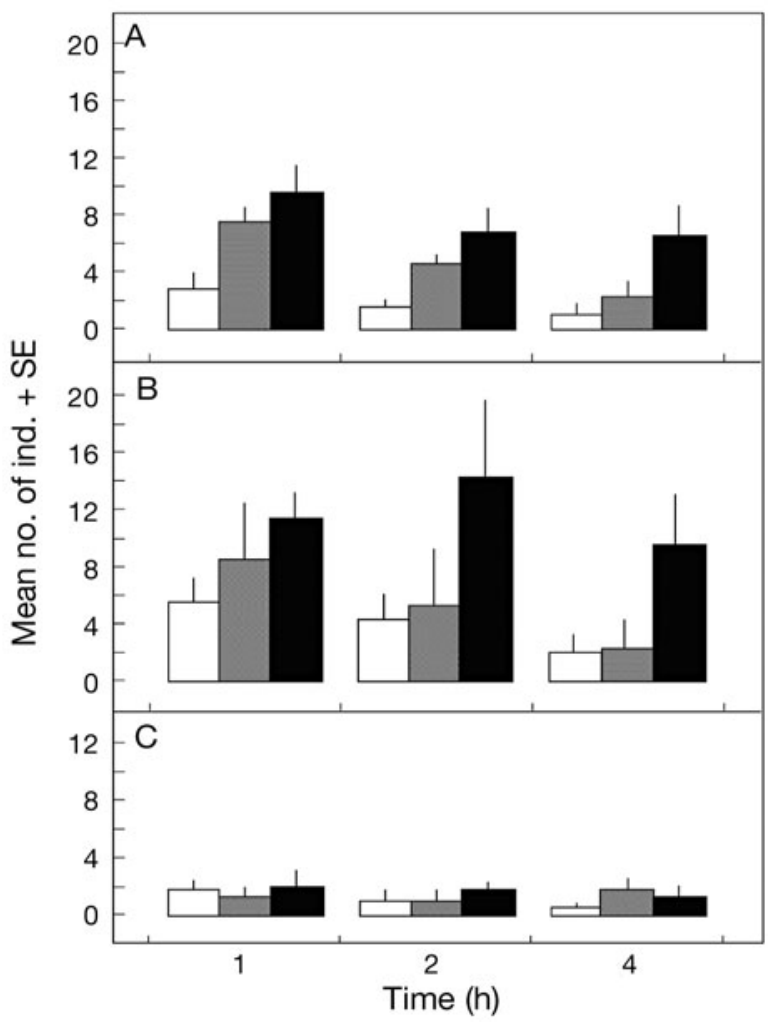

Fig. 5. Macomona liliana. Number of juveniles that had not burrowed in each treatment [0 d TS (run A), $7 \mathrm{~d}$ TS (run B), and $14 \mathrm{~d}$ TS (run C)] at 1, 2 and $4 \mathrm{~h}$ after their addition to the aquaria. Fifty individuals were added to each aquarium. White bars: control sediment treatment; grey bars: buried TS treatment; black bars: surface TS treatment

Table 7. Results of repeated measures ANOVA to investigate the effects of treatments/runs on Macomona liliana burrowing. Multiple comparisons: Tukey's tests; TS-s: surface terrestrial sediment, TS-b: buried terrestrial sediment, and C: control sediment treatments. Trt: treatment; ns: not significantly different $(\mathrm{p}>0.05)$

\begin{tabular}{|c|c|c|c|c|c|c|c|}
\hline Run (TS age) & Time & $\operatorname{Pr}>F$ & $F$-value & MS & SS & $\mathrm{df}$ & Multiple comparisons \\
\hline \multirow[t]{6}{*}{$A(0 d)$} & Trt & 0.0002 & 20.30 & 332.53 & 997.58 & 3 & \\
\hline & Time $\times$ Trt & 0.0003 & 7.93 & 14.03 & 84.18 & 6 & \\
\hline & Error (Time) & & & 1.77 & 31.83 & 18 & \\
\hline & $1 \mathrm{~h}$ & $<0.0001$ & 26.89 & 205.42 & 616.25 & 3 & TS-s, TS-b > TS-b, C \\
\hline & $2 \mathrm{~h}$ & 0.0003 & 20.04 & 90.75 & 272.25 & 3 & TS-s, TS-b > TS-b, C \\
\hline & $4 \mathrm{~h}$ & 0.0058 & 8.31 & 64.42 & 193.25 & 3 & TS-s, TS-b > TS-b, C \\
\hline \multirow[t]{3}{*}{$B(7 d)$} & Trt & 0.0242 & 5.49 & 495.47 & 1486.42 & 3 & TS-s, TS-b > TS-b, C \\
\hline & Time $\times$ Trt & 0.0558 & 2.65 & 18.22 & 109.33 & 6 & \\
\hline & Error (Time) & & & 6.88 & 110.00 & 16 & \\
\hline \multirow{3}{*}{$C(14 \mathrm{~d})$} & Trt & 0.0233 & 5.21 & 22.92 & 68.75 & 3 & ns \\
\hline & Time $\times$ Trt & 0.3267 & 1.25 & 0.92 & 5.50 & 6 & \\
\hline & Error (Time) & & & 0.73 & 13.17 & 18 & \\
\hline
\end{tabular}


burrowing of post-settlement juvenile bivalves. Our measurements of changes in surface and near-surface porewater chemistry (diffusivity, $\mathrm{O}_{2}$ and $\mathrm{pH}$ ) were investigated at the micro-scale, i.e. at and near the sediment-water interface-a scale likely to be important to a potential small, post-settlement colonist. In combination, these results provide (1) a mechanistic understanding of the observed negative responses of soft-sediment macrofauna to sedimentation events (Cummings et al. 2003, Cummings \& Thrush 2004, Lohrer et al. 2004), and (2) some insight into the potential cues used by post-settlement juvenile bivalves to determine the suitability of a habitat for settlement.

The main effect of surface TS deposits was a change (decrease) in the penetration depth of $\mathrm{O}_{2}$ (measured from the deposit-sediment interface to the depth of the anoxic sediment), and in the porewater $\mathrm{O}_{2}$ concentrations and $\mathrm{pH}$ (Tables $3 \& 6$ ). Supply of $\mathrm{O}_{2}$ to the sediment underlying the TS deposit is essential for the oxidation of reduced end products of mineralisation in the sediment column, and prevents these reduced end products from diffusing upward towards the surface sediments where the juveniles are active. Oxygen consumption in control sediments was partly due to oxic respiration (microbial decomposition of organic matter using oxygen as the electron acceptor) and oxidation of reduced end products of anaerobic decomposition of organic matter (e.g. sulfides, $\mathrm{Mn}^{2+}$ ). The latter processes cause maximum $\mathrm{O}_{2}$ consumption and minimum $\mathrm{pH}$ near the oxic-anoxic boundary. Addition of a surface TS deposit decreased the penetration depth of $\mathrm{O}_{2}$ so that the oxic-anoxic boundary (the zone where reduced solutes are oxidized) shifted upwards, closer to the surface of the sediment. Thus, the likelihood of infauna residing in near-surface sediments being exposed to upward diffusing end products of microbial decomposition was increased. $\mathrm{pH}$ was also lowered due to oxidation of reduced solutes diffusing from below. A negative correlation was observed between the apparent diffusivity of the TS-surface deposit and $\mathrm{O}_{2}$ consumption in the deposit-underlying sediment. A similar correlation between the rate at which TSsurface deposits reduced the total (deposit + underlying sediment) $\mathrm{O}_{2}$ consumption and the TS-surface diffusivity was not observed (Table $6, \Delta R$ ), indicating that the $\mathrm{O}_{2}$ consumption zone had simply shifted.

The supply of $\mathrm{O}_{2}$ to the deposit-underlying control sediment is affected by the diffusivity of the TS deposit. Weathering of TS increased its diffusivity (Table 3); consequently, the $\mathrm{O}_{2}$ consumption of the underlying sediment also increased (Table 6). Both the $\mathrm{O}_{2}$ consumption of sediment underlying the TS-surface (Table 6) and the diffusivity of the TS-surface deposit (Table 3) increased with TS age (correlations were 0.984 and 0.961 , respectively). The greater diffusivity might have resulted in higher diffusion of $\mathrm{O}_{2}$ from the bottom water down into the sediment, and presumably, also of reduced solutes (e.g. sulfides, $\mathrm{Mn}^{2+}$ ) from sediment porewater up into the bottom water. As TS diffusivity increased, the oxic-anoxic boundary might have shifted downwards into the sediment where other reactions (e.g. calcite dissolution and sulfide oxidation by $\mathrm{Fe}(\mathrm{OH})_{3}$ ) could have buffered against proton production processes.

Surface and buried deposits of fresh and weathered TS were incorporated into this experiment because (1) over time, surface TS deposits may become gradually buried as they get covered by ambient sediment transported as bedload (Norkko et al. 2002), and (2) there is a positive correlation between macrofaunal colonisation and the length of time the TS remains on the sandflat (see Cummings et al. 2003, Lohrer et al. 2004). As expected, burrowing by Macomona liliana juveniles into surface TS deposits was significantly reduced (Fig. 5, Table 7), and the strength of this response was influenced by the age of the deposits. Fewer juveniles burrowed into the 0 and $7 \mathrm{~d}$ TSsurface treatments compared with the control sediment treatments, but burial was not affected by the oldest (14 d) TS-surface treatment (Table 7, Fig. 5).

While the bivalves were clearly negatively affected by surface TS treatments relative to controls, the response to these very thin deposits was not as strong as that observed in previous experiments involving 5 to $10 \mathrm{~mm}$ TS layers, which also demonstrated reduced burrowing into treatments with buried ( $5 \mathrm{~mm}$ thick) TS deposits (Cummings \& Thrush 2004). In this experiment, Macomona liliana burrowing was not affected by TS-buried treatments of any age (Table 7 ). This difference is not surprising given that the chemical responses detected here are likely to be magnified in thicker deposits.

We expected that the effect of surface TS deposits on juvenile Macomona liliana burrowing would be strongest in the $0 \mathrm{~d}$ TS-surface treatment and weaken with TS weathering. While more individuals burrowed in the most weathered (14 d) TS, we noted that burial was lower in the $7 \mathrm{~d}$ TS relative to the $0 \mathrm{~d}$ TS treatment (Fig. 5). Due to our experimental design, it is not appropriate to statistically test for differences in burial at different TS ages. As expected, the reduction in $\mathrm{O}_{2}$ consumption, $R$ (i.e. $\Delta R$-surface), caused by a $1 \mathrm{~mm}$ thick TS-surface deposit relative to control sediment was greatest when fresh $(0 \mathrm{~d})$ TS was applied, because these deposits had the lowest diffusivity (Table 6). Unexpectedly, however, the weakest reduction in $R$ was caused by the $7 \mathrm{~d}$ TS rather than the $14 \mathrm{~d}$ TS deposits (Table 6). The relatively high $R$ in these treatments (i.e. relatively low $\Delta R$ ) may be due to a higher $\mathrm{O}_{2}$ consumption in the $7 \mathrm{~d}$ TS-surface deposit (Table 6). 
This could have resulted from, e.g. a higher organic content in the $7 \mathrm{~d} \mathrm{TS}$, which would in turn elevate carbon oxidation, and/or enhance oxidation of reduced inorganic species (e.g. $\mathrm{H}_{2} \mathrm{~S}, \mathrm{Mn}^{2+}, \mathrm{Fe}^{2+}$ ) diffusing upwards from the underlying sediment. A potentially higher flux of reduced species from the sediment into the $7 \mathrm{~d}$ TS-surface deposit was in fact indicated by the higher $\Delta \mathrm{pH}$ of the control sediment underlying the $7 \mathrm{~d}$ TS-surface layer compared to that underlying the $0 \mathrm{~d}$ or $14 \mathrm{~d}$ TS-surface treatments (Table 3). Unfortunately, however, organic content was not measured so this inference cannot be confirmed.

Studies by Woodin et al. (1995), Woodin (1998) and Marinelli \& Woodin $(2002,2004)$ found correlations between short-term changes in concentrations of porewater oxygen and ammonium in response to smallscale disturbance, and burrowing response of postsettlement bivalves and polychaetes. The results of our study provide further evidence of the link between sediment chemistry and post-settlement behaviour, and point to the importance of $\mathrm{pH}$ in reflecting this response. For example, the toxicity of sulphide to aerobic organisms increases with decreasing $\mathrm{pH}$ (see Vismann 1996, and references therein). Lower $\mathrm{pH}$ has also been shown to decrease porewater $\left[\mathrm{CO}_{3}{ }^{2-}\right]$, resulting in carbonate undersaturation and mortality of juvenile Mercenaria mercenaria ( 0.2 to $1 \mathrm{~mm}$ ) due to shell dissolution over day timescales (Green et al. 2004). The differences in $\Delta \mathrm{pH}$ in these experiments relate to the $\mathrm{pH}$ at $>1 \mathrm{~mm}$ depth; for an individual to respond to such differences requires the transfer of a chemical signal to the surface of the sediment, or detection via sensors in some part of the bivalve (e.g. foot) below the sediment surface. No pre-burrowing substrate 'testing' (e.g. use of the foot to probe the substrate) by juvenile Macomona liliana was observed in these experiments, nor was there any attempt to initiate dispersal (sensu Cummings et al. 1993). Rather, they either remained stationary on the sediment surface, or buried.

The design of our laboratory experiments involved simplification of the environment actually experienced by post-settlement juvenile bivalves on an intertidal sandflat. Firstly, defaunated sandflat sediments were used, so the effect of activities of other animals (e.g. burrowing and feeding by polychaetes) that would likely disrupt the sediment layers, and thus influence the solute gradients in the sediment-water interface, was not considered. Secondly, the experiments were conducted in low velocity flow that was steady and unidirectional, which are conditions far removed from those in the more turbulent, dynamic sandflat. However, the responses to the TS treatments used in the experiment may still be applicable in a more realistic environment. Traces of experimental deposits of $1 \mathrm{~mm}$ thick TS remained after $10 \mathrm{~d}$ on a sandflat (Lohrer et al.
2004). Irrespective of their persistence time in the field, even relatively short-term exposure to TS $(<1 \mathrm{~d})$ is long enough to negatively affect infauna (Cummings \& Thrush 2004). Compared to previous experiments using thicker layers of TS, the magnitudes of the effects on bivalve burrowing noted in our experiments are low (maximum non-burial rates of $20 \%$ ). However, these differences are likely to be significant at the population level, and will be magnified if organisms are exposed to repeated disturbance by frequent, albeit small, TS depositions.

In conclusion, our study has shown how millimeterthin deposits of terrigenous sediments can affect the chemistry of the sediment-water interface and the burrowing of post-settlement juvenile bivalves. The results suggest that further investigations on $\mathrm{pH}$ and associated geochemical species may be useful in elucidating cues used by post-settlement bivalves, and indeed by other macrofauna, in determining habitat suitability.

Acknowledgements. We thank P. Marriott, D. Thistle and A. Vopel for comments on an earlier version of this manuscript. Three anonymous reviewers and R. Osman provided comments that further improved the manuscript. This research was funded by the New Zealand Foundation for Research, Science and Technology, contract nos. CO1X037 and CO1X0305.

\section{LITERATURE CITED}

Bagarinao T (1992) Sulfide as an environmental factor and toxicant: tolerance and adaptations in aquatic organisms. Aquat Toxicol 24:21-62

Ben-Yaakov S (1973) pH buffering of pore water of recent anoxic marine sediments. Limnol Oceanogr 18:86-94

Berg P, Risgaard-Petersen N, Rysgaard S (1998) Interpretation of measured concentration profiles in sediment pore water. Limnol Oceanogr 43:1500-1510

Beukema J, Vlas JD (1989) Tidal-current transport of threaddrifting postlarval juveniles of the bivalve Macoma balthica from the Wadden Sea to the North Sea. Mar Ecol Prog Ser 52:193-200

Boudreau BP, Canfield DE (1988) A provisional diagenetic model for $\mathrm{pH}$ in anoxic porewaters: application to the FOAM site. J Mar Sci 46:429-455

Broecker WS, Peng TH (1974) Gas exchange rates between air and sea. Tellus 26:185-190

Butman C (1987) Larval settlement of soft-sediment invertebrates: the spatial scales of pattern explained by active habitat selection and the emerging role of hydrodynamical processes. Oceanogr Mar Biol Annu Rev 25: 113-165

Commito JA, Thrush SF, Pridmore RD, Hewitt JE, Cummings VJ (1995) Dispersal dynamics in a wind-driven benthic system. Limnol Oceanogr 40:1513-1518

Cummings VJ, Thrush SF (2004) Behavioural response of juvenile bivalves to terrestrial sediment deposits: implications for post-disturbance recolonisation. Mar Ecol Prog Ser 278:179-191

Cummings VJ, Pridmore RD, Thrush SF, Hewitt JE (1993) 
Emergence and floating behaviours of post-settlement juveniles of Macomona liliana (Bivalvia: Tellinacea). Mar Behav Physiol 24:25-32

> Cummings VJ, Pridmore RD, Thrush SF, Hewitt JE (1996) Effect of the spionid polychaete Boccardia syrtis on the distribution and survival of juvenile Macomona liliana (Bivalvia: Tellinacea). Mar Biol 126:91-98

Cummings V, Thrush S, Hewitt J, Norkko A, Pickmere S (2003) Terrestrial deposits on intertidal sandflats: sediment characteristics as indicators of habitat suitability for recolonising macrofauna. Mar Ecol Prog Ser 253:39-54

Dahms HU, Harder T, Qian PY (2004) Effect of meiofauna on macrofauna recruitment: settlement inhibition of the polychaete Hydroides elegans by the harpacticoid copepod Tisbe japonica. J Exp Mar Biol Ecol 311:47-61

Dayton PK, Mordida BJ, Bacon F (1994) Polar marine communities. Am Zool 34:90-99

Emerson C, Grant J (1991) The control of soft-shell clam (Mya arenaria) recruitment on intertidal sandflats by bedload sediment transport. Limnol Oceanogr 36:1288-1300

> Gazeau F, Quiblier C, Jansen JM, Gattuso JP, Middelburg JJ, Heip CHR (2007) Impact of elevated $\mathrm{CO}_{2}$ on shellfish calcification. Geophys Res Lett 34:L07603 doi:10.1029/ 2006GL028554

Glud RN, Berg P, Fossing H, Jørgensen BB (2007) Effects of the diffusive boundary layer on benthic mineralization and $\mathrm{O}_{2}$ distribution: a theoretical model analysis. Limnol Oceanogr 52:547-557

Green MA, Jones ME, Boudreau CL, Moore RL, Westman BA (2004) Dissolution mortality of juvenile bivalves in coastal marine deposits. Limnol Oceanogr 49:727-734

> Gunther CP (1992) Dispersal of intertidal invertebrates: a strategy to react to disturbances of different scales? Neth J Sea Res 30:45-56

Jørgensen BB, Boudreau BP (2001) Diagenesis and sediment-water exchange. In: Boudreau BP, Jørgensen BB (eds) The benthic boundary layer: transport processes and biogeochemistry. Oxford University Press, p 211-244

Jørgensen BB, Des Marais DJ (1990) The diffusive boundary layer of sediments: oxygen microgradients over a microbial mat. Limnol Oceanogr 35:1343-1355

Jørgensen BB, Revsbech NP (1985) Diffusive boundary layers and the oxygen uptake of sediments and detritus. Limnol Oceanogr 30:111-122

> Jourabchi P, Van Cappellen P, Regnier P (2005) Quantitative interpretation of $\mathrm{pH}$ distributions in aquatic sediments: a reaction-transport modeling approach. Am J Sci 305: 919-956

Kleypas JA, Feely RA, Fabry VJ, Langdon C, Sabine CL, Robbins LL (2006) Impacts of ocean acidification on coral reefs and other marine calcifiers: a guide for future research. Report of a workshop sponsored by NSF, NOAA, and the US Geological Survey, 18-20 April 2005, St. Petersburg, FL, p 88

Lohrer AM, Thrush SF, Hewitt JE, Berkenbusch K, Ahrens M, Cummings VJ (2004) Terrestrially derived sediment: response of marine macrobenthic communities to thin terrigenous deposits. Mar Ecol Prog Ser 273:121-138

Marinelli RL, Woodin SA (2002) Experimental evidence for linkages between infaunal recruitment, disturbance, and sediment surface chemistry. Limnol Oceanogr 47:221-229

Marinelli RL, Woodin SA (2004) Disturbance and recruitment: a test of solute and substrate specificity using Mercenaria mercenaria and Capitella sp. 1. Mar Ecol Prog Ser 269: 209-221

Milliman JD, Meade RH (1983) World-wide delivery of river sediment to the oceans. J Geol 91:1-21

Nilsson PG, Levinton JS, Kurdziel JP (2000) Migration of a

Editorial responsibility: Richard Osman,

Edgewater, Maryland, USA marine oligochaete: induction of dispersal and microhabitat choice. Mar Ecol Prog Ser 207:89-96

Norkko A, Cummings VJ, Thrush SF, Hewitt JE, Hume T (2001) Local dispersal of juvenile bivalves: implications for sandflat biology. Mar Ecol Prog Ser 212:131-144

Norkko A, Thrush SF, Hewitt JE, Cummings VJ and others (2002) Smothering of estuarine sandflats by terrigenous clay: the role of wind-wave disturbance and bioturbation in site-dependent macrofaunal recovery. Mar Ecol Prog Ser 234:23-41

Olivier F, Desroy N, Retiere C (1996) Habitat selection and adult-recruit interactions in Pectinaria koreni (Malmgren) (Annelida: Polychaeta) post-larval populations: results of flume experiments. J Mar Res 36:217-226

Rasmussen H, Jørgensen BB (1992) Microelectrode studies of seasonal oxygen uptake in a coastal sediment: role of molecular diffusion. Mar Ecol Prog Ser 81:289-303

Revsbech NP (1989) An oxygen microsensor with a guard cathode. Limnol Oceanogr 34:474-478

Revsbech NP, Nielsen LP, Ramsing NB (1998) A novel microsensor for determination of apparent diffusivity in sediments. Limnol Oceanogr 43:986-992

SAS Institute (1999) SAS/STAT users guide, Version 8. Cary, NC

Sigurdsson J, Titman C, Davies P (1976) The dispersal of young post-larval bivalve molluscs by byssus threads. Nature 262:386-387

Stocks KI (2002) Flume experiments on post-settlement movement in polychaetes. J Mar Res 60:743-762

> Stocks KI, Grassle JF (2001) Effects of microalgae and food limitation on the recolonization of benthic macrofauna into in situ saltmarsh-pond mesocosms. Mar Ecol Prog Ser 221: 93-104

> Thrush SF, Hewitt JE, Norkko A, Nicholls PE, Funnell GA, Ellis JI (2003) Habitat change in estuaries: predicting broad-scale responses of intertidal macrofauna to sediment mud content. Mar Ecol Prog Ser 263:101-112

> Thrush SF, Hewitt JE, Cummings VJ, Ellis JI, Hatton C, Lohrer AM, Norkko A (2004) Muddy waters: elevating sediment input to coastal and estuarine habitats. Front Ecol Environ 2:299-306

Vismann B (1996) Sulfide species and total sulfide toxicity in the shrimp Crangon crangon. J Exp Mar Biol Ecol 204: 141-154

- Vopel K, Vopel A, Thistle D, Hancock N (2007) Effects of spatangoid heart urchins on $\mathrm{O}_{2}$ supply into coastal sediment. Mar Ecol Prog Ser 333:161-171

Williamson RB, Wilcock RJ, Wise BE, Pickmere SE (1999) Effect of burrowing by the crab Helice crassa on chemistry of intertidal muddy sediments. Environ Toxicol Chem 18(9):2078-2086

> Woodin SA (1985) Effects of defecation by arenicolid polychaete adults on spionid polychaete juveniles in field experiments: selective settlement or differential mortality. J Exp Mar Biol Ecol 87:119-132

> Woodin SA (1998) Process-specific cues for recruitment in sedimentary environments: geochemical signals? J Mar Res 56:535-558

Woodin SA, Marinelli RL, Lincoln DE (1993) Allelochemical inhibition of recruitment in a sedimentary assemblage. J Chem Ecol 19:517-529

- Woodin SA, Lindsay SM, Wethey DS (1995) Process-specific recruitment cues in marine sedimentary systems. Biol Bull 189:49-58

Yuan-Hui L, Gregory S (1974) Diffusion of ions in sea water and in deep-sea sediments. Geochim Cosmochim Acta 38:703-714 